\title{
Fotografía del inconsciente por Frank Diamond Waleska Barroeta
}

Espejo menos que escalofrí [... a la vez pausa y caricia, pasaje de unarco líquido en un concierto de espuma Paul Claudel rank Diamond, fotógrafo artístico español y entusiasta de la simbología, descubrió su gusto por el arte cuando era aún un niño, pintando al óleo y experimentando. Muchos años después, encontró un medio que le ha permitido transmitir una original forma de ver el mundo, una cámara y diversas herramientas de edición. A partir de entonces, se enfocó en aprender de forma autodidacta todo lo que estaba a su alcance para comunicar al universo aquello que vivía en las aguas de su inconsciente. 
El hilo conductor de su obra es de carácter extremadamente personal, pues, asegura, usa la creación como medio para enfrentar sus propias emociones. Frank tiende a restar protagonismo a los rostros en su trabajo y se concentra en ocasiones en la forma mediante la cual se funden los cabellos con el viento y en cómo la naturaleza envuelve a la mujer hasta que es imperceptible la línea entre lo real y lo creado. Esto ha llamado la atención tanto del público como de sus pares, y le ha llevado a ser entrevistado por numerosos medios como Kluid Magazine, Cultura Inquieta, Adobe Lightroom, Instagram España, DNG Photo Magazine, Neo2 Magazine, Adobe Photoshop y Digital SLR Photography Magazine. Su trayectoria no para de impresionar, ya que a su corta edad ha colaborado en diversas galerías dentro y fuera de España. En 2017 publicó su primer fotolibro Instinct, una serie de fotografías que combinan su amor por la mitología y la poesía.

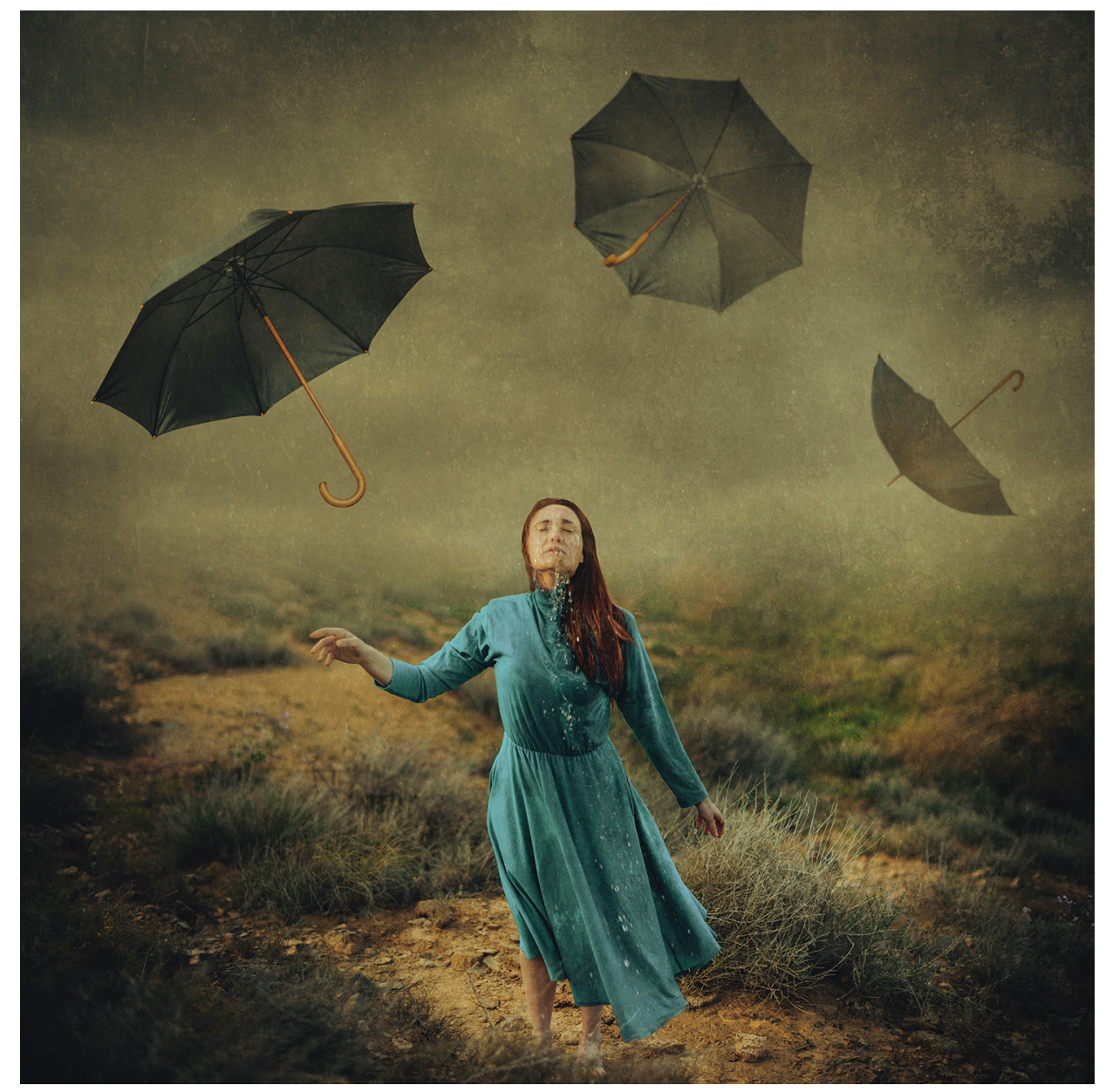

Emotional deluge (2018). Fotografía Fine Art: Frank Diamond. Prohibida su reproducción en obras derivadas. 


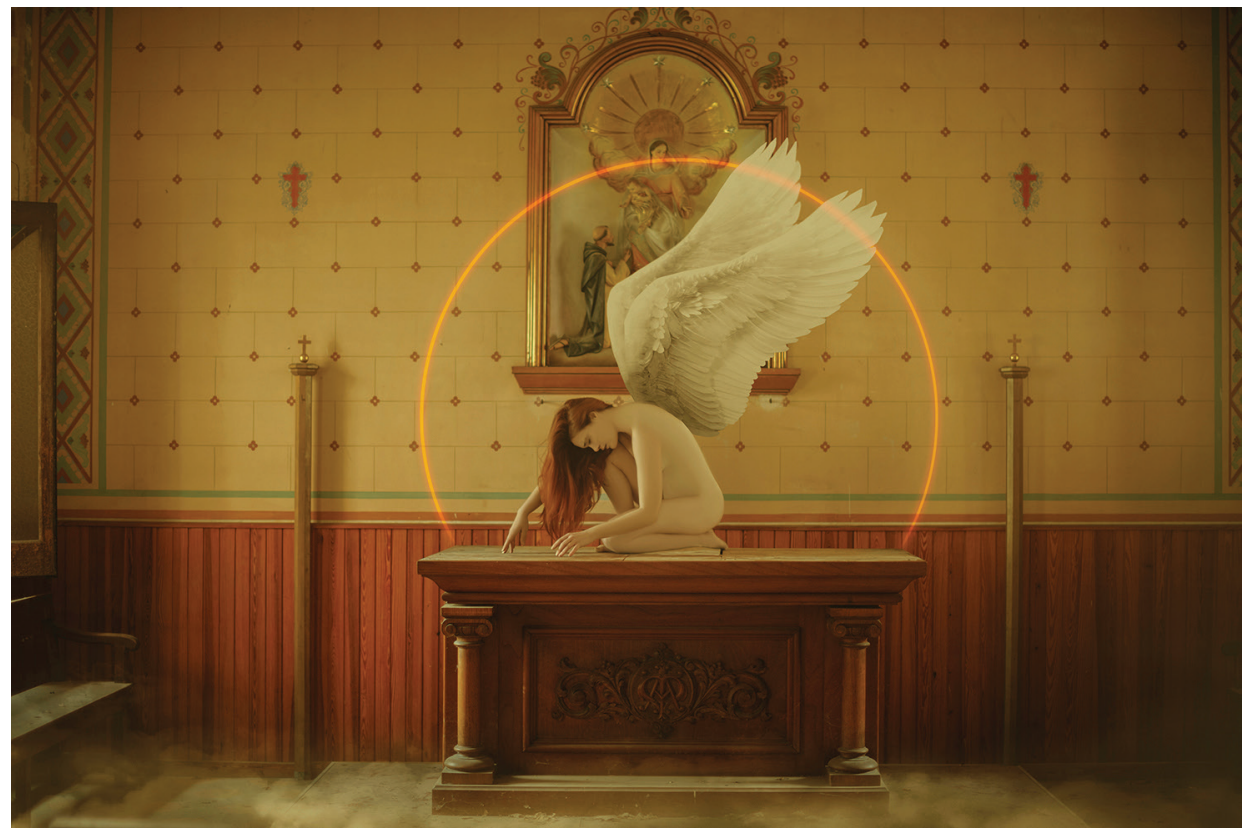

Angelo (2018). Fotografía Fine Art: Frank Diamond.

Prohibida su reproducción en obras derivadas.

Actualmente, es uno de los más talentosos fotógrafos españoles autodidactas. Sus inicios le llevaron a incursionar en el autorretrato como primer contacto, por lo que viajó a lo más profundo de sus miedos para marcar una tendencia que combina lo fantástico y lo tenebroso, dando a luz un nuevo mundo de espejos, aves y misterio.

Su obra refleja una concepción sobrepersonal del arte, convirtiendo éste, en sus propias palabras, en una especie de diario visual. La minuciosa selección expuesta en esta edición de La Colmena juega con la noción de reflejo (Broken memories, 2015; In the mirror, 2018; Reflejos II, 2021) y su conexión como símbolo primitivo del agua (Introspección, 2017) que evoluciona en el espejo, lo que lleva al espectador por un viaje a las profundidades del inconsciente y la imaginación. Las posibilidades son infinitas al observar cómo el fotógrafo es capaz de hacer caer al espectador por el agujero en persecución del conejo blanco.

El elemento más uniforme, los sujetos sobrenaturales y volubles de cada foto, refiere múltiples historias mitológicas, Narciso, las vigilantes aves de Apolo o, incluso, el cuervo que acompaña a Cronos. El artista tiene una particular técnica basada en el uso de la luz como elemento dramático, la cual, al perderse en la niebla, otorga uniformidad a esta serie. Cada imagen posee un tono y una coloración diferente, pero mantiene una textura que las une y en ello radica la magia Diamond. 


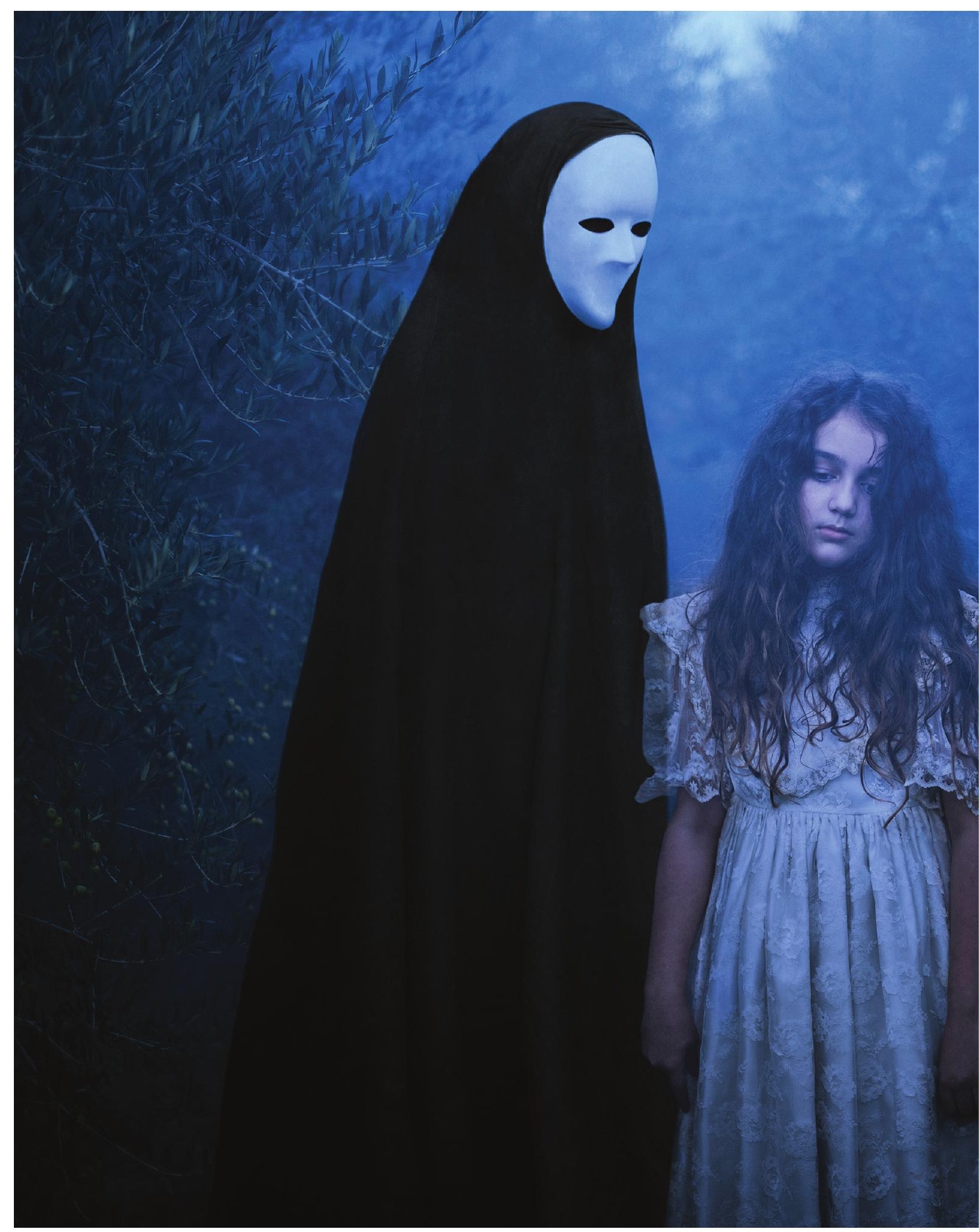




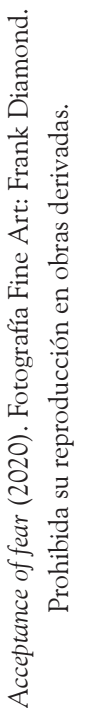




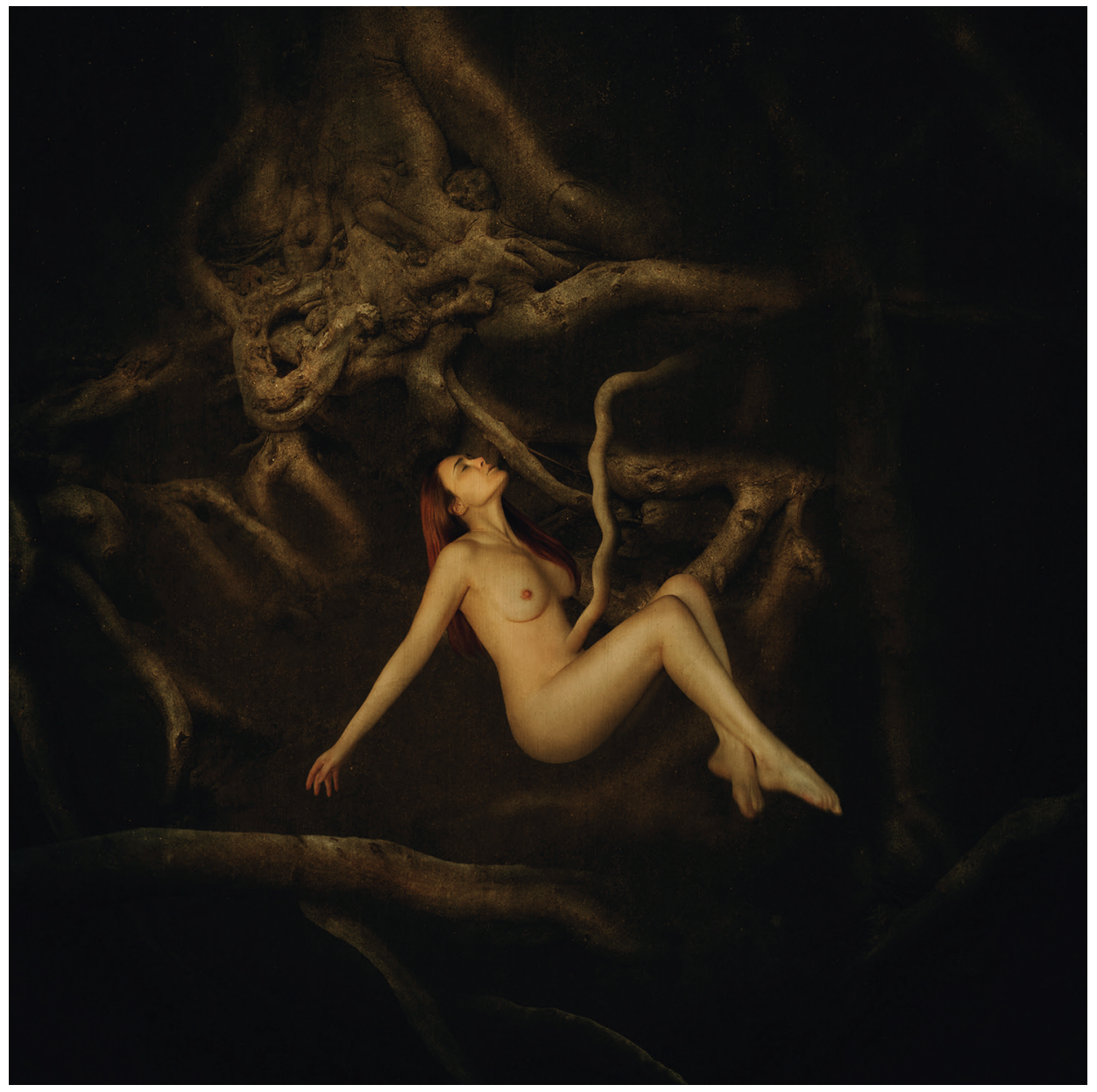

Útero (2018). Fotografía Fine Art: Frank Diamond.

Prohibida su reproducción en obras derivadas.

Asimismo, por medio de la lente y usando diversos programas de edición para romper con las limitantes de la realidad, despliega una atmósfera distópica y desconcertante. Las mujeres de blanca tez fotografiadas dan la ilusión de estar al borde de la muerte como si hubiesen sido creadas por el mismísimo Horacio Quiroga. Estas Alicias lucen rodeadas de las plumas de sus almohadones, plumas que no podrían ser más lúgubres, pues pertenecen a aves de carroña, lo que alude a un sentimiento de desesperación que hace olvidar por un momento que no se está en una pesadilla y crea el perfecto canal entre la realidad y la ficción. Sin embargo, dichas aves también recuerdan la incapacidad de escapar cuando se es un ser sin alas. Esta clara desesperación se puede observar en Crosses (2018) y, aún más significativamente, en obras como Release the pain (2019) y Dark feather (2016). 
Un vínculo conecta a estas imágenes y nos relata una fantástica historia sin gravedad ni tiempos, al tiempo que estructura una tétrica pero tentadora narrativa, una lengua que conserva su peculiar coloración y hace una constante reflexión acerca de qué tan lejos se puede llegar para transmitir una pesadilla sin caer en películas de horror. Lo realmente espantoso de un mal sueño es la incapacidad que tiene el sujeto para percatarse de que está, en efecto, soñando, y Frank Diamond nos deja con el recordatorio de cuán frágiles somos ante los mares de la mente.

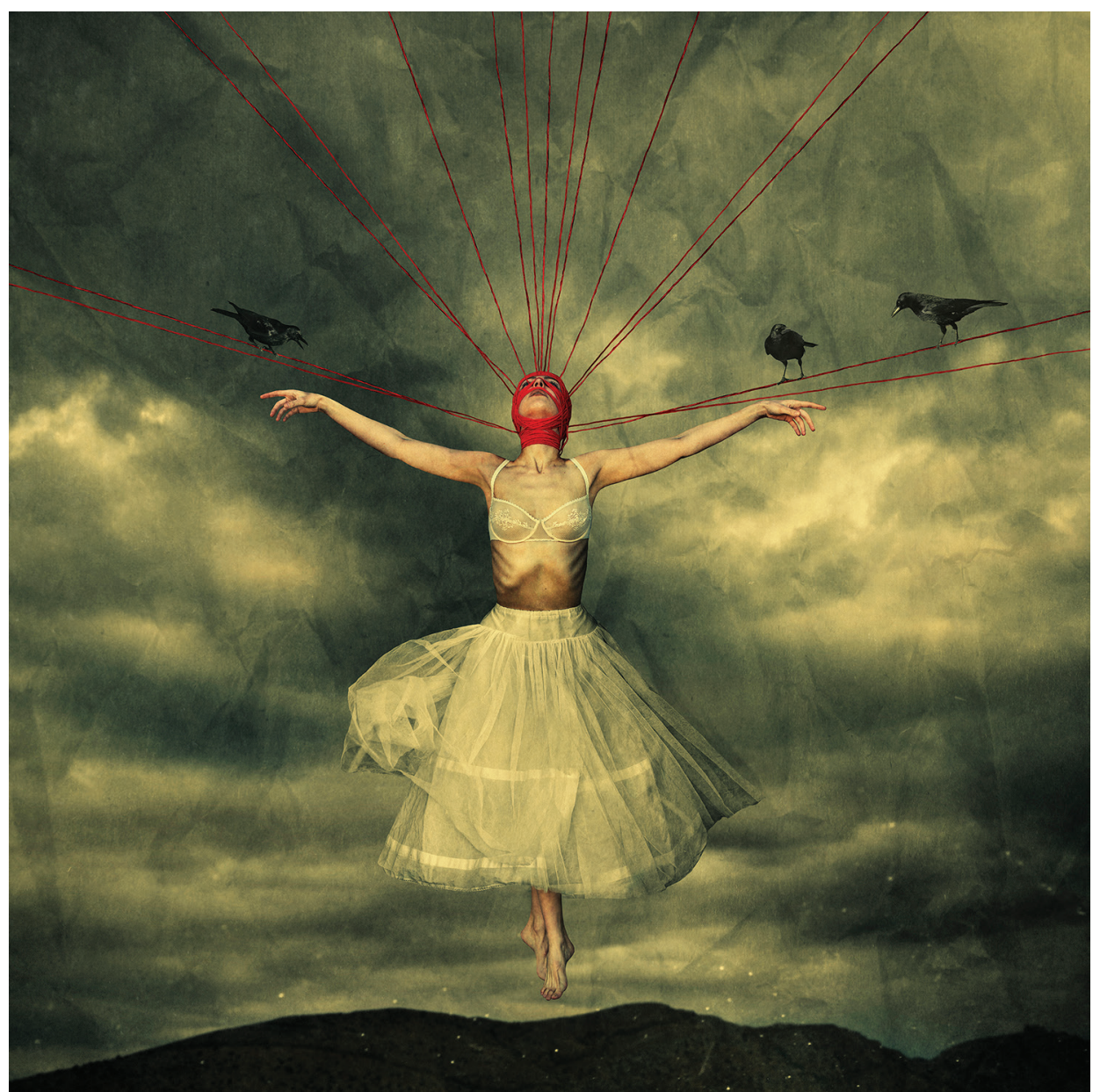

Veins (2019). Fotografía Fine Art: Frank Diamond.

Prohibida su reproducción en obras derivadas. 

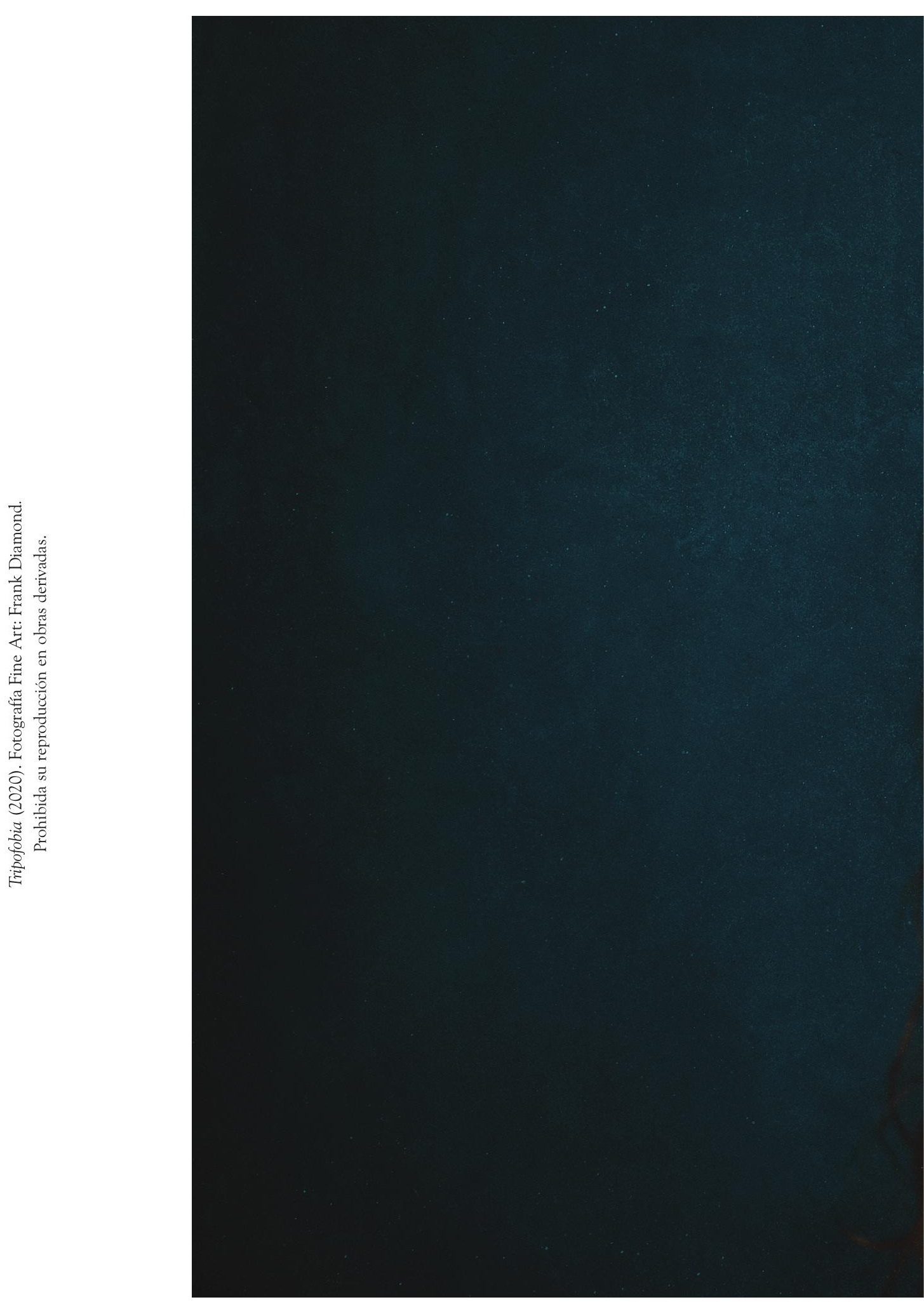


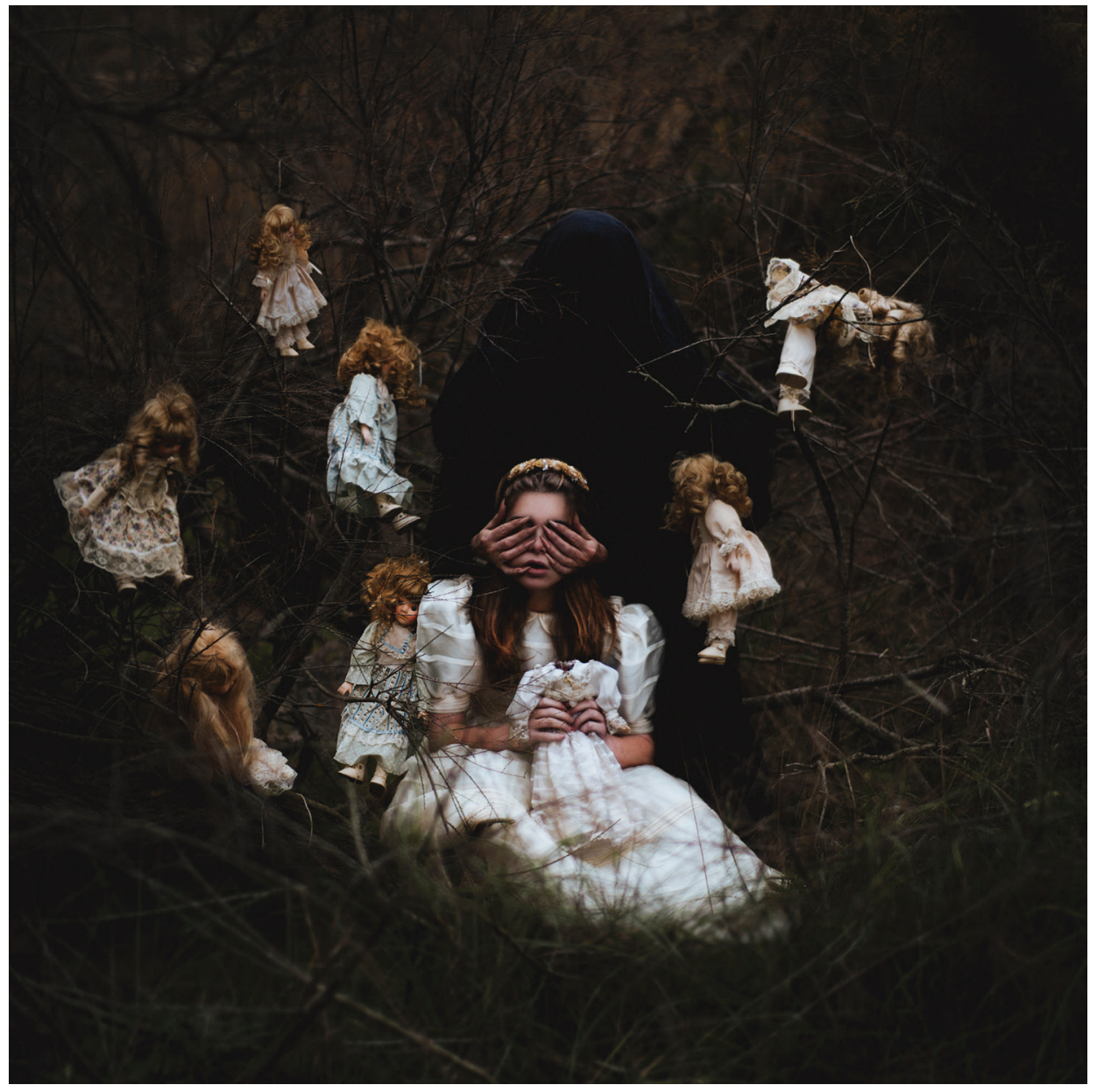

They come for me (2015). Fotografía Fine Art: Frank Diamond.

Prohibida su reproducción en obras derivadas. 


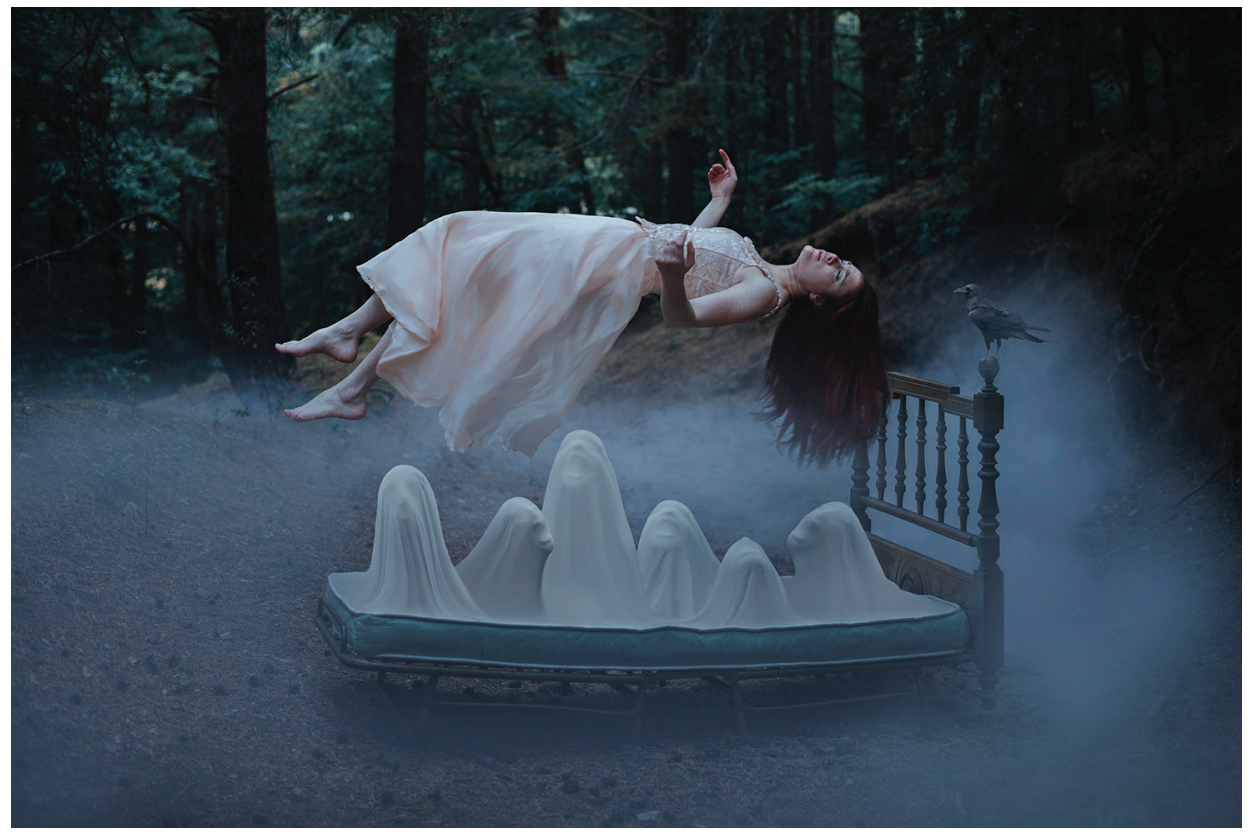

The other side (2017). Fotografía Fine Art: Frank Diamond.

Prohibida su reproducción en obras derivadas.

FRANK DiAmond. Con varios años en el mundo del arte, se ha especializado en fotografía artística, en particular en el fotomontaje. Ha sido presentado en diversas galerías de arte y cuenta con varias exposiciones a nivel nacional e internacional. Ha publicado un libro. Debido a su prometedora trayectoria, varios portales digitales y otros medios de prensa lo han entrevistado.

WALESKa BARROETA. Escritora, profesora, conferencista y prologuista venezolana. Licenciada en Lengua y Literatura Hispánicas por parte de la Universidad Autónoma del Estado de México (UAEM), México, graduada con mención honorífica con la tesis Estructura arquetípica y mítico-simbólica en Doña Bárbara de Rómulo Gallegos. Apasionada de la poesía y el psicoanálisis. Se ha dedicado a la difusión cultural en medios impresos y digitales y ha apoyado en exposiciones literarias, como FestínARTE y el Programa Cultura en Movimiento de la Dirección de Cultura del Ayuntamiento de Toluca, desde 2019.

Recibido: 19 de enero de 2021

Aprobado: 26 de febrero de 2021 